\title{
Cambios en las pautas de consumo alimentario en España
}

\author{
Francisco Entrena Durán \\ Universidad de Granada
}

\section{Resumen}

Las pautas de consumo alimentario en España están siendo alteradas como consecuencia del proceso de desarrollo económico, de modernización de la sociedad en general y de globalización de su agricultura experimentado a lo largo de las últimas décadas. Tanto la incorporación de nuestro país a la Comunidad Europea como la reciente firma de los acuerdos del GATT son factores que han contribuido a acelerar y a consolidar la tendencia hacia la globalización. Los valores y patrones sobre los que se asientan estas nuevas pautas de consumo están en consonancia con los planteamientos de un modelo posfordista de producción que busca la calidad y la competitividad. Este modelo resulta adecuado para satisfacer las demandas de unos consumidores cuyo más elevado nivel de vida les hace ser más exigentes, pero también para los requerimientos estandarizados con referencia a normas de calidad, de presentación o de envasado de los productos que se imponen a escala mundial, así como para la imagen corporal y los estilos de vida propiciados por la nueva situación productiva más sedentaria y divulgados por la publicidad y los medios de comunicación de masas, con una creciente incidencia a este respecto.

En esta situación, las diferencias sociales y de status ya no se simbolizan, para muchos, tanto en el hecho de no "pasar hambre» o de poder alimentarse mejor como en el de su posibilidad de acceso diferencial a determinados bienes (elaborados según la recomendación de los "expertos» o las normas de cocinado y de presentación de publicaciones consideradas como "prestigiosas"), de consumir productos de "agricultura ecológica», o de comer en ciertos restaurantes a los que otros con menor nivel económico no pueden ir. Se trata de manifestar una diferenciación/identificación (emulación de status) ante el grupo o estrato social con respecto al que el sujeto consumidor pretende desvincularse o adherirse simbólicamente en su práctica cotidiana del hecho social de nutrirse.

Palabras clave: consumo alimentario, globalización, postfordismo, desarrollo económico.

\section{Abstract. Change in the food consume in Spain}

Food consumepatterns in Spain have changed according to the process of economic development and modernization as well as globalization of Spanish agriculture and the entrance into the European Community.

Key words: food consume, globalization, postfordism, economic development 


\section{Sumario}

Globalización y creciente homogeneización mundial de la dieta alimentaria

Desarrollo económico y transformaciones en la dieta alimentaria española

Del fordismo al posfordismo: la opción por la calidad y la competitividad
Búsqueda de la «calidad» o de la identidad de status: nuevas modalidades de construcción y de manifestación social diferencial de las pautas de consumo alimentario

Bibliografía

\section{Globalización y creciente homogeneización mundial de la dieta alimentaria}

Con frecuencia se habla de la "dieta mediterránea" como si fuera una forma de alimentación común y generalizada para todos los países ribereños del Mediterráneo. El hecho de que la zona geográfica en la que se ubica nuestro país tenga unas determinadas condiciones agroclimáticas y esté especializada en la producción de alimentos como legumbres secas, hortalizas, frutas, aceite de oliva o vinos parece que debería ocasionar un mayor consumo de tales productos en relación con otros países que no pertenecen a este entorno (Titos, 1992: 5 y s.). Esto daría lugar a cierta semejanza en la dieta de tales países, semejanza que indudablemente existió en tiempos pasados.

No obstante, hace ya tiempo que el consumo alimentario dejó de depender básicamente de la producción autóctona de cada uno de los países, dado el creciente desarrollo de los intercambios comerciales internacionales. Entre los factores que han originado los cambios en el consumo alimentario cabe destacar aquí la progresiva urbanización e industralización, que ha ocasionado que cada vez se consuman más productos transformados y la extensión de los hábitos sociales de «imitacion-igualación» por los que los grupos de países más pobres tienden a imitar y equipararse en las pautas de consumo a los más ricos.

La gradual relegación de la "dieta mediterránea" por parte de nuestro país y su progresiva equiparación, en lo que a hábitos de consumo alimentario se refiere, con el resto del mundo tiene lugar en el marco de la creciente integración de la agricultura y de la sociedacl españolas en la imprevisible dinámica globalizadora en la que las presentes sociedades se hallan cada vez más insertas. En ellas, lo local tiende apresuradamente a perder importancia al mismo tiempo que se reafirma el peso de lo global. La globalización se muestra en los planos económico-social, político-institucional y simbólico-legitimador (Entrena, 1995). En el nivel económico-social, la mutua interdependencia de los países y regiones está creciendo enormemente. Las acciones localizadas de determinados grupos están teniendo cada vez más consecuencias para contornos sociales y espaciales de ámbito más global ${ }^{1}$. En nuestro contexto geopolítico, tanto la

1. Consideremos, por ejemplo, la contaminación del aire y del agua que está amenazando la calidad de vida de regiones enteras de Europa Central, o los cambios climáticos derivados de la deforestación de la selva amazónica (Veerman, 1994: 315). 
incorporación a la Comunidad Europea como la reciente firma del GATT (Acuerdo General sobre Aranceles y Comercio) son factores que han contribuido a acelerar un proceso generalizado a escala planetaria según el cual se tiende a pasar de un mercado nacional a otro mundial. En lo político-institucional, se está experimentando una apresurada expansión de movimientos e instituciones, de estructuras de relaciones y de diferentes organizaciones de naturaleza transnacional que está haciendo las fronteras entre los países más permeables y penetrables por los influjos externos (Robertson, 1993: 5). Ello está conllevando una paulatina disminución de la soberanía y de la capacidad de maniobra de los Estados nacionales (Held, 1991: 178-179). Las tendencias que apuntan hacia la consolidación de la unidad europea constituyen, en nuestro entorno sociopolítico más cercano, un indicador y un efecto de esta propensión hacia la cada vez mayor transnacionalidad de lo político-institucional. Por último, en lo simbólico-legitimador se genera una sociedad crecientemente estandarizada en lo cultural, en las formas de pensar y de actuar, y en los hábitos de comportamiento. En lo que se refiere al tema que constituye el objeto de estudio de este trabajo, la globalización se muestra en una creciente homogeneización mundial de las pautas de consumo y de las actitudes psicosociales ante él.

La globalización de la agricultura y del sector agroalimentario en España ha estado decisivamente influida por acontecimientos recientes como la conformación de un nuevo escenario internacional resultante de la puesta en marcha del mercado único europeo, de la entrada en vigor de la reforma de la Política Agraria Comunitaria (PAC) de 1992 y de la tendencia al gradual abandono de su tradicional orientación proteccionista, así como de la conclusión de las negociaciones encaminadas a la aprobación del GATT. Sin embargo, para entender cabalmente las actuales pautas de consumo, aparte de su inevitable vinculación con la paulatina inserción de la sociedad española en la sociedad global, hay que pasar revista también (aunque sea someramente) al proceso de desarrollo económico que ha dado lugar a ellas.

\section{Desarrollo económico y transformaciones en la dieta alimentaria española}

Durante las últimas décadas se han producido en España importantes modificaciones en el consumo de alimentos que se han manifestado tanto en lo relativo a la proporción del gasto dedicado a este cometido como en lo referente a la composición de la dieta y al grado de elaboración de los alimentos consumidos (Abad y García Delgado, 1990: 125 y s). Como suele suceder en los procesos de crecimiento y de desarrollo económico, se ha ido experimentando una paulatina reducción de la proporción relativa del gasto familiar dedicado a la alimentación, que pasó desde niveles cercanos al $50 \%$ a mediados de la década de los sesenta al $30 \%$ veinte años después. Paralelamente a ello, los incrementos de la renta por habitante durante las décadas de los sesenta y setenta originaron un cambio muy considerable en la composición de la dieta ali- 
menticia que, de estar integrada por productos tradicionales tales como cereales panificables, tubérculos, legumbres o aceites, fue progresivamente incorporando un creciente consumo de carne, pescado, leche, huevos y derivados lácteos. De esta forma, no sólo aumentó el contenido en calorías totales de la dieta, sino que también se produjo un considerable proceso de reemplazo de energía y de proteínas vegetales por las derivadas de los productos ganaderos. Así, en el período de tiempo comprendido entre 1965 y 1982 se multiplicó por dos la aportación a la dieta proporcionada por los productos de origen animal, que suponía en 1982 un $30 \%$ de la energía total consumida. Por contra, la aportación energética de los cereales descendió en ese período en más de un $30 \%$. En lo que se refiere a la composición proteínica del consumo alimentario, las proteínas de procedencia animal se duplicaron, llegando a representar en los primeros años ochenta un $60 \%$ de las proteínas totales consumidas; aumento que permitió compensar el descenso de las proteínas vegetales e, incluso, incrementar en un $20 \%$ el consumo proteínico total.

A partir de la segunda mitad de los setenta comenzó a ralentizarse el ritmo expansivo del gasto alimentario que había caracterizado el proceso de crecimiento económico producido desde los años cincuenta. En los inicios de los ochenta se produjo incluso un cierto retroceso en dicho gasto. Desde esas fechas y en lo que respecta a la oferta alimentaria se experimentó un acercamiento de la agricultura española a la situación de equilibrio excedentario característica de la mayoría de las agriculturas de los países europeos. Con toda probabilidad, el descenso del gasto se debió a que ya en 1975 los balances alimentarios mostraban que las necesidades básicas de ingestión de calorías y de proteínas (en torno a 2800 calorías y 90-100 gramos de proteínas por persona y día) se encontaban ya suficientemente satisfechas, habiéndose ya producido la superación de las carencias y limitaciones típicas de un modelo tradicional de economía de subsistencia. En gran parte, también, el descenso en el gasto alimentario ha estado motivado por la implantación generalizada de unos roles ocupacionales que conllevan, habitualmente, unas formas de vida más sedentarias que requieren menor consumo de calorías y también puede ser explicado como consecuencia del escaso grado de crecimiento de la población total y de su progresivo envejecimiento.

Así como la saturación en el consurno de nutrientes se pone de manifiesto en el descenso de un $10 \%$ de las calorías totales y en la estabilización de la cantidad de proteínas en la dieta entre 1975 y 1982, pueden también apreciarse tasas de crecimiento anual acumulativo negativas en la primera mitad de los ochenta para el consumo por habitante de casi todos los grupos de productos, exceptuando los huevos, las frutas frescas y las legumbres secas (Abad y García Delgado, 1990: 128-129).

Los considerables cambios ocurridos en nuestro país a raíz del desarrollo económico (niveles de renta superiores, movimientos migratorios, desarrollo de los medios de transporte y de comunicación social, creciente incorporación de la mujer al mundo del trabajo, reducción del tamaño medio de la unidad familiar, etc.) han repercutido en que se produzca una modificación de las pau- 
tas de consumo alimentario (SAC, 1993: 33). Especialmente, la incorporación de la mujer al mundo laboral es también un factor crucial para entender las nuevas pautas de consumo alimentario en España. Las tareas del hogar tienen que ser realizadas en menos tiempo y ello ha redundado en una creciente expansión del mercado de comidas precocinadas, al mismo tiempo que ha ido paralelo a la introducción de la tecnología en las actividades culinarias cotidianas del hogar (frigoríficos, exprimidoras automáticas de zumo, trituradoras, hornos eléctricos, etc.) y ha implicado la disposición de un mayor nivel adquisitivo para consumo en general, lo que hace que, aunque aumente el gasto absoluto en consumo alimentario, éste tienda a disminuir en términos relativos. El aumento de tal gasto se tradujo al principio, en la práctica, en una ingesta muy superior a las necesidades estrictas del individuo medio y fundamentada, sobre todo, en un elevado consurno de proteínas y de calorías.

Posteriormente, una vez satisfechas las necesidades materiales básicas, los hábitos de consumo se dirigen hacia la búsqueda de una mejora de la calidad de vida y alimentaria. Ello no es óbice para que siga aumentando el montante de dinero dedicado a la alimentación, en la que, continuando la tendencia comenzada en 1992, el gasto total ascendió durante el año 1993 a 7,7 billones de pesetas, con un incremento del 2,5\% respecto del ańo anterior (UPA, 1994: 114). Estas cifras incluyen el gasto de los hogares, el consumo institucional -hospitales, cuarteles, cárceles, etc.- y las compras realizadas por los establecimientos de hostelería y restauración, sin incluir, por lo tanto, el gasto final de los consumidores en este tipo de establecimientos. En concreto, durante 1993 aumentó el consumo en el hogar pero decreció el gasto realizado en hostelería y restaurantes. El valor total de los alimentos comprados por los hogares ascendió a 6 billones de pesetas, mientras que el gasto de hostelería, restauración e instituciones llegó a situarse en torno a 1,7 billones de pesetas. De acuerdo con estos datos, la participación en el gasto alimentario del consumo del hogar supuso un $78 \%$ frente a un $75 \%$ en 1992 . Por su parte, el gasto de hostelería y restauración decreció y pasó de un $23 \%$ en 1992 a un $20 \%$ en 1993. De esta forma, el gasto por habitante en los hogares experimentó un aumento del 5,8\%, situándose en 153.000 pesetas por persona y año. En cuanto a las diferencias regionales, al igual que en anteriores años, las regiones del noreste, el norte y Castilla y León se mantuvieron por encima del promedio nacional, en contraste con Andalucía, Levante, el noroeste, y especialmente Canarias, que permanecieron por debajo.

Finalmente, si se clasifica el gasto dedicado a alimentación de acuerdo con el grado de elaboración de los alimentos, se patentiza claramente que a lo largo de las cuatro últimas décadas (sobre todo, en los pasados diez años) se ha experimentado una creciente importancia de la demanda de aquellos productos que son objeto de sucesivos procesos de preparación o de transformación antes de llegar al consumidor final y se distinguen por una acusada diferenciación e imagen de marca. En contraste, el consumo de productos con escaso grado de elaboración (el pan, las harinas, los aceites y las grasas) ha decrecido drásticamente en comparación con los años cincuenta. Por su parte, los productos 
transformados no tradicionales (carne fresca, leche fresca, azúcar), a pesar de sus bajos niveles de diferenciación, han seguido representando una elevada proporción de gasto alimentario dada su alta elasticidad de renta dentro del grupo de bienes alimenticios.

Aunque desvirtuada por un exceso de proteínas de origen animal, nuestra dieta conserva todavía rasgos típicos del ámbito mediterráneo en el que se ubica (HSAC, 1995: 44). Asimismo, como consecuencia de la incorporación de España a la Comunidad Europea, se ha experimentado un proceso de convergencia, según el cual, al mismo tiempo que aquí se adoptan pautas alimentarias típicas de los países del norte de la Comunidad, éstos tienden a incrementar el consumo de hortalizas característico del Mediterráneo. En cualquier caso, esta convergencia alimentaria nunca será total, ya que factores culturales, históricos y climáticos mantendrán algunas diferencias (Gracia y Albisu, 1994).

\section{Del fordismo al posfordismo:}

\section{la opción por la calidad y la competitividad}

Cuando en este trabajo se habla de opción por la calidad, por parte de los consumidores, se hace referencia al hecho de que, una vez satisfechas las necesidades materiales básicas, los hábitos dé consumo han tendido a dirigirse hacia la búsqueda de una mejora de las condiciones de vida y alimentarias, así como a orientarse de acuerdo con valores culturales de naturaleza posmaterialista (Inglehart, 1991). Sin embargo, aquí también se alude a la "calidad" como elemento diferenciador de status o para hacer referencia a la creciente dependencia de la imagen (criterios de presentación o envasado establecidos, generalmente, por las grandes corporaciones transnacionales de la alimentación y fomentado su consumo por la publicidad).

Estos cambios en las pautas de consumo alimentario acontecen en un contexto en el que, en el escenario relativamente local europeo, está siendo reemplazado el clásico sistema proteccionista de naturaleza «fordista» (es decir, basado en la elaboración masiva de productos homogéneos) por un modelo productivo que, ante la saturación de los mercados alimentarios, enfatiza, entre otros aspectos, la extensificación productiva, la calidad, el diseńo, la especialización y la competitividad (posfordismo). El tránsito del fordismo al posfordismo es, también, un efecto de la necesidad de adaptación de una economía de superproducción y de relativa saturación de la oferta que requiere el arraigo de la tendencia a incentivar el consumo y el gasto. En lo que se refiere a este último, en el nuevo contexto posfordista es esperable que tenga lugar un ligero aumento durante los años venideros, que se basará fundamentalmente en un tipo de consumo orientado, sobre todo, hacia la demanda de productos de "calidad" (alimentos sin aditivos, con denominación de origen, productos de «agricultura ecológica", etc.) y hacia el incremento del consumo realizado fuera del hogar si la evolución de la situación económica es favorable a ello, pues, en los últimos años, se ha observado una cierta res- 
tricción de esta forma de gasto debida a la falta de expectativas derivadas de la crisis.

Mientras en España y en el contexto general de Europa y de los países desarrollados arraigan estas tendencias posfordistas, favorables a restringir la producción en el espacio rural y a dedicar éste a otros usos diferentes del mero cultivo agrario, a escala mundial se viene observando desde 1984 un gradual descenso en la elaboración de alimentos (Veerman, 1994: 318). Ello resulta extremadamente preocupante si se tiene en cuenta el estado de miseria en el que se encuentra la gran mayoría de la población del planeta y la apremiante necesidad de producir más recursos que genera un descontrolado y acelerado crecimiento de los habitantes de la Tierra.

El nuevo modelo posfordista está cada vez más vinculado a un ámbito económico global que opera a escala planetaria, en el que arraigan paulatinamente las reglas de juego de las grandes corporaciones transnacionales que, de una u otra forma, tratan de propiciar unas formas y cotas de producción alimentaria en consonancia con el mantenimiento de un nivel de precios acorde con sus intereses. Dichas corporaciones tratan de extender su control a todos los eslabones de la cadena alimentaria de comercialización y de consumo. La paulatina penetración de las corporaciones transnacionales en el sector del consumo alimentario está originando como efecto más inmediato una creciente presión sobre diversos actores sociales y grupos económicos tradicionalmente implicados en este sector, tales como la industria alimentaria y el tradicional comercio minorista de venta de bienes de consumo, en el que se viene observando a lo largo de los últimos años una constante disminución del número de establecimientos (Lamo de Espinosa, 1994: 305). La supervivencia de dichos grupos económicos se encuentra, en muchos casos, amenazada, ya que debido a su bajo grado de competitividad se ven abocados a una competencia desigual con tales corporaciones, cuyas normas de "calidad" y de "competitividad" conectan mejor con las demandas de los consumidores (e, incluso, tienen capacidad para fomentarlas a través de la publicidad). La concentración del comercio alimentario español de distribución final al consumidor está aún bastante por debajo de la media europea (gráficos I y II).

En tales circunstancias, una de las actuaciones estratégicas de la política agroalimentaria española se orienta hacia el fomento de la elaboración de productos de alta calidad, adecuados para satisfacer las crecientes exigencias de los consumidores en este sentido, que reclaman una mayor diversificación de la oferta alimentaria (SAC, 1993: 36). El reto está en lograr que esta política de diversificación y de búsqueda de la calidad pueda contribuir eficazmente a resolver los problemas de los mercados excedentarios. Uno de los mecanismos básicos de tal política son las denominaciones de calidad (denominaciones de origen, genéricas y específicas), que acreditan la calidad y la personalidad de diversos productos de acuerdo con su origen, medio geográfico o agroclimático, variedades o razas y sistemas de elaboración. Según datos de 1991, el valor económico de la comercialización de productos amparados por denominaciones de origen, específicas y genéricas, alcanzó en España la cifra de 252.413 
Cuota de mercado (\% volumen de ventas)

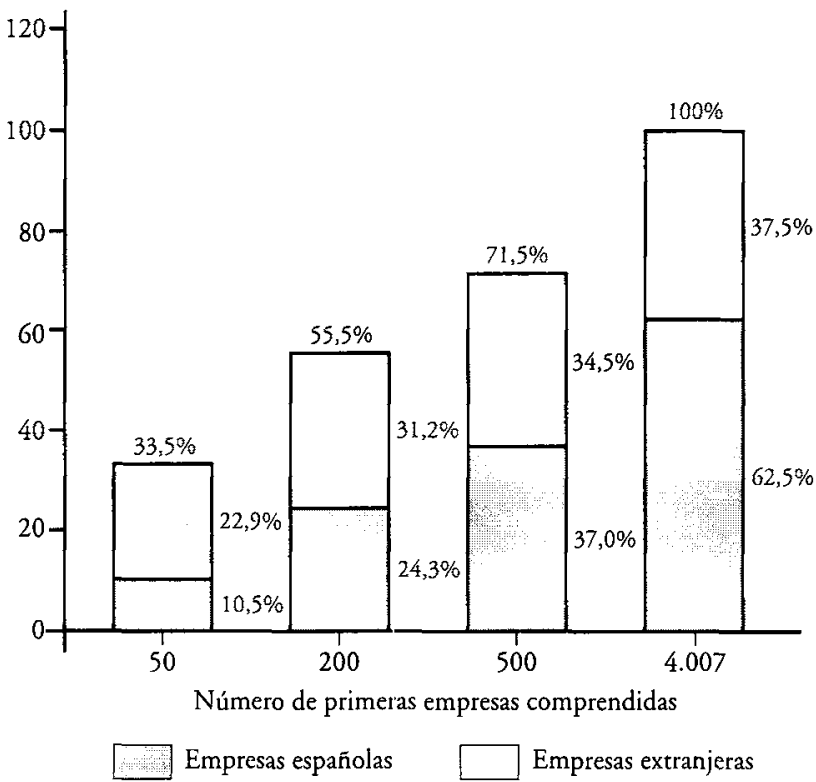

Gráfico I. Concentración del sector de alimentación y bebidas en España. Ventas totales del sector en $1992=7.503 .377$ millones de pesetas. Número total de empresas $=4.007$. Fuente: Allmarket-93.

millones de pesetas, de los que 178.593 provenían del mercado interior y los 73.850 restantes de las exportaciones. Esto nos da una idea de la importancia que está adquiriendo en nuestro país la tendencia a optar por unas pautas de consumo que buscan la calidad.

Búsqueda de la «calidad» o de la identidad de status: nuevas modalidades de construcción y de manifestación social diferencial de las pautas de consumo alimentario

La cada vez más acentuada búsqueda de la "calidad» se está desarrollando en un contexto de paulatina extensión del mercado de los platos precocinados, de los potenciadores de sabor, de los conservantes y de otros diversos aditivos que manifiestan unos procesos más complejos de elaboración de los alimentos, ya sea con fines de conservación, meramente estéticos, de búsqueda de nuevas presentaciones del producto o culinarios. Ello redunda en una gradual pérdida de autonomía de los consumidores como actores sociales en lo que se refiere a la determinación de sus pautas alimenticias que, progresivamente, incrementan sus niveles de dependencia respecto de las empresas alimentarias 


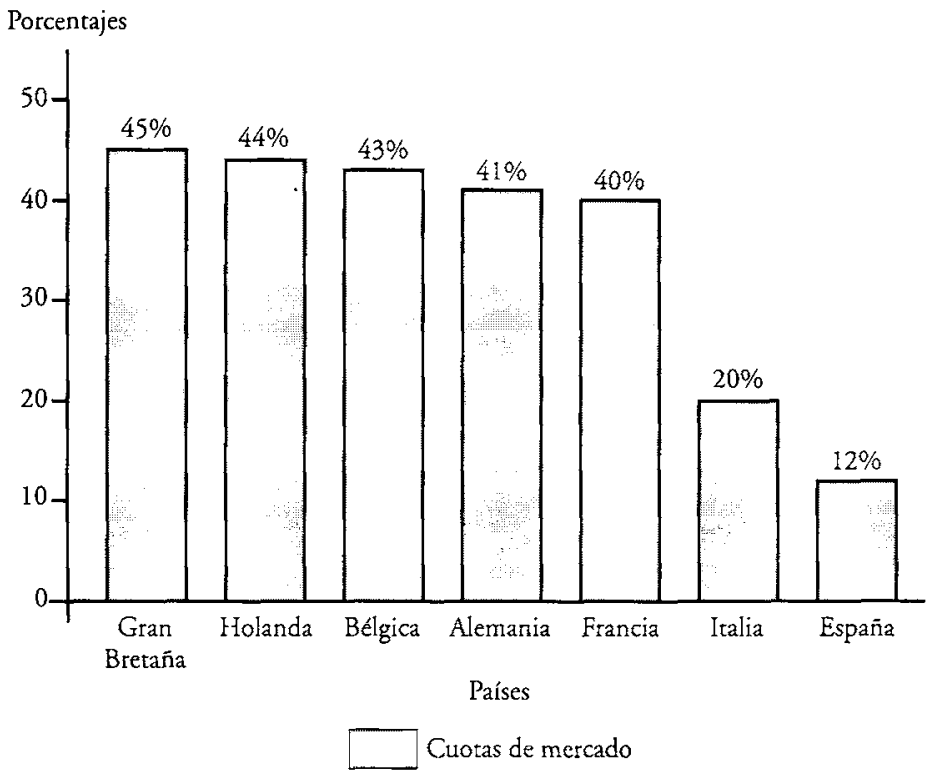

Gráfico II. La concentración del comercio alimentario europeo. Fuente: elaboración propia según datos de febrero de 1992 del instituto francés SECODIP (datos citados por F. Ramos Real [1993: 155]).

dedicadas a estos procesos de transformación. De esta forma, lo que desde cierta óptica se presenta como un aumento de la "calidad» alimentaria, como una liberación al tener que dedicar menos tiempo a las otrora rutinarias y dilatadas tareas diarias de preparación y cocinado de los alimentos, se muestra, paradójicamente, también como una creciente colonización del cotidiano «mundo de la vida» de la gente por parte del cada vez más potente y estandarizado a nivel global planetario «sistema» alimentario ${ }^{2}$.

Por otra parte, las nuevas pautas de consumo manifiestan que con su adopción está teniendo lugar algo mucho más complejo que la mera superación de las carencias características de la tradicional economía de subsistencia. Así, se aprecia una tendencia gradual a pasar a unas formas de consumo que reflejan en la población que demanda o compra ciertos productos determinados hábitos o estilos de vida en consonancia con los nuevos modos de presentación de las personas en la vida cotidiana (Goffman) que hoy sirven como paradigmas de referencia de la identificación colectiva y de la diferenciación social.

Toda realidad social se construye socialmente. En ella intervienen unos actores que forman parte más o menos activa de una sociedad (según el grado de

2. Los conceptos de "colonización", de "mundo de la vida" y de "sístema" son concebidos aquí de manera similar a como lo hace Habermas (1987: 451 y siguientes). 
participación efectiva que propicia el orden en el que están inmersos) y que, con mayor o menor nivel de consciencia, son artífices y/o portadores de un discurso social legitimador de sus comportamientos, actitudes y expectativas. La opción por la «competitividad" y por la "calidad» posfordistas tiene lugar paralelamente al afianzamiento de una tendencia hacia la generalización de una nuevas modalidades de construcción y de manifestación social diferencial de la realidad de las pautas de consumo. La construcción social de la realidad (Berger y Luckmann) sobre la que opera la actual situación de producción y de consumo posfordista se incardina en el contexto de la superproducción, de la búsqueda de la identidad a través de la diferenciación y de la especificidad en un mundo cada vez más estandarizado y sujeto, en lo que a sus pautas de consumo se refiere, a las consignas homogeneizadoras de una publicidad y de unos medios de comunicación de masas que ejercen su influjo a nivel planetario. Un mundo (un campo, en la terminología de Bourdieu) que requiere nuevos roles ocupacionales y tiene estilos de vida más sedentarios (a pesar de que en él se viaja más que nunca), al mismo tiempo que fomenta el culto al cuerpo como un objeto cada vez menos conformado por lo biológico y más por unas condiciones sociales y culturales (Shilling, 1993). Esta situación propicia nuevos usos acerca de lo que se entiende por gusto y por rango social. El habitus de comportamiento y/o las actitudes inherentes a las diferencias sociales de status o a la "distinción» (Bourdieu), en lo que a la alimentación se refiere, ya no se simbolizan para muchos tanto por la posibilidad de no "pasar hambre" y de poder alimentarse mejor (en el marco de carencias típicas de las tradicionales economías de subsistencia limitada a las clases altas, a los «ricos» ${ }^{3}$ ), como por la circunstancia de gozar de una situación económica que permite un acceso y/o disfrute diferencial a determinados productos de mayor calidad ${ }^{4}$. Considerada ésta, ya sea por el grado de elaboración de esos productos, ya porque los mismos son "más naturales» o de "agricultura ecológica", o poque son consumidos en determinados restaurantes a los que otros con menor nivel económico no pueden ir. De esta forma, la opción por la "calidad» alimentaria se erige en un elemento de búsqueda de la identidad de status a través de la adopción de pautas de consumo que simbolizan la diferenciación, la vinculación o la sintonía con cierto grupo social, la manifestación de un nivel socioeconómico específico.

Antes, en las sociedades insertas en la economía de autosubsistencia, la estratificación social se mostraba a través de la exclusión o la imposibilidad de con-

3. Por ejemplo, en las tradicionales economias de subsistencia, dentro de las que se enmarcaba la realidad de nuestro país hace unos cuarenta años, era corriente que sólo los "ricos» pudieran comer carne con regularidad.

4. El autor es plenamente consciente que lo que se afirma aquí es sólo cierto para aquellos sectores sociales del mundo relativamente desarrollado inmersos en la economía de superproducción. Sin embargo, la situación que se acaba de describir se torna en escandalosa cuando se toma en consideración el penosci estado de miseria y de carencias que sufre esa gran mayoría de la población del planeta excluida de los beneficios del desarrollo, de la que incluso en España, a tenor de las estadísticas, existe una considerable proporción. 
sumir lo suficiente para satisfacer las necesidades básicas del organismo, hoy dicha diferenciación es, sobre todo, una cuestión de manifestar la internalización del habitus de "saber elegir con buen gusto» el producto más idóneo, el restaurante adecuado (generalmente el recomendado en el medio de comunicación que sirve de referencia dominante para reflejar el status socioeconómico de un específico grupo social), de optar por un determinado diseño del producto o del envase, etc. 5 .

La calidad, más que algo determinado en función del valor intrínseco del producto, suele estar en muchos casos asociada a factores como la imagen derivada de su forma de elaboración, de su envoltura o de su presentación final. Los criterios de determinación de la "calidad" son establecidos, frecuentemente, por el influjo de la publicidad y de los medios de comunicación de masas escritos (revistas, suplementos semanales de ciertos periódicos) o, especialmente, los audiovisuales (televisión, radio). La publicidad alimentaria se erige de este modo en un instrumento de estandarización y de homogeneizacion (simultaneada con la permanencia y/o el fomento de una cierta diversidad dirigida a facilitar las ventas en un mercado cada vez más saturado) de los hábitos alimentarios a nivel mundial, al divulgar unas pautas de consumo cada vez más en consonancia con los intereses y los requerimientos comerciales de las grandes corporaciones transnacionales del sector.

En un sector (generalmente, entre aquellos grupos sociales cuyo nivel cultural les lleva a un mayor grado de "racionalización" de sus comportamientos) los hábitos de consumo alimentario se realizan de acuerdo con esquemas de conducta encuadrables dentro de lo que Baudrillard (1976) ha conceptuado como la génesis ideológica de las necesidades, desarrollada a partir de la seducción que ejerce sobre las conciencias el contenido más o menos elaborado de los discursos de determinados "peritos» en la materia divulgados a través de unos medios o formas de comunicación de carácter relativamente selectivo o elitista. En otras muchas ocasiones, las pautas de consumo colectivo manifiestan una génesis con frecuencia pulsional, emotiva, derivada de la mera instantaneidad del mensaje publicitario audiovisual o gráfico. No obstante, tanto en el primero como en el segundo caso, se trata (independientemente de que exista o no una estrategia consciente y racionalmente planificada para ello) de inducir a la población a determinados hábitos a los que se atribuye una carga simbólica significativa y atractiva.

La adopción de unas determindas pautas de consumo alimentario suele ser al mismo tiempo reflejo de dos actitudes entre las que existe una contradictoria relación dialéctica; se trata de la diferenciación o la emulación de status. Diferenciación de los hábitos alimentarios de aquel grúpo o estrato social del que el sujeto consumidor trata de desvincularse simbólicamente a través del

5. La búsqueda del diseño es observable, incluso, en una manera de cultivar el producto tendente a que adquiera una determinada forma; por ejemplo, tomates, manzanas u otros frutos que se procura que lleguen al mercado con figuras geométricas casi perfectamente regulares. 
hecho social de alimentarse y, por otra parte, emulación del status y de los comportamientos o supuestos conocimientos en lo relativo a "calidad" y al "bien comer" del sector social con el que dicho sujeto pretende identificarse simbólicamente. La dialéctica diferenciación/emulación es característica tanto de los consumidores que siguen los medios masivos de comunicación y de publicidad como de aquellos que, más o menos intencionadamente, buscan la «distinción» en sus hábitos alimenticios respecto del común de las masas y suelen ser más selectivos en sus criterios de determinación de las pautas de consumo alimentario que actúan como referentes a partir de los que construir/manifestar su identidad.

Tradicionalmente, estos referentes de "distinción" y de "buen gusto" eran por lo usual transmitidos hereditariamente a través de la socialización de clase que, por lo general, estaba encomendada a la familia. En nuestros días, la televisión (para el común de las masas) o las revistas "prestigiosas" y el consejo de los «entendidos» (para los que ahora aspiran a la exquisitez, y en definitiva a la «distinción») están reemplazando, en muchos casos, ese papel socializador de clase en otros tiempos asumido por la familia. En un mundo en el que la lectura, la cultura y el acceso a los medios de comunicación se ha hecho un fenómeno de masas, existen bastantes posibilidades para que se produzca una democratización/homogeneización de los hábitos alimentarios del «bien comen". Muchas veces las actitudes de diferenciación/emulación conllevan que en la práctica no se va más allá de consumir los mismos productos que el común de la gente. La diferencia está en que el medio de acceso a ellos (el supermercado común, un restaurante de moda para un determinado grupo social, una tienda «especializada») tiene un carácter más o menos masificado, en que son preparados de acuerdo con una receta de cocina corriente, recomendada en determinado medio de comunicación de «renombre» o siguiendo al cocinero («experto») de turno.

La tentativa de buscar la "distinción» a través de la adopción de ciertas pautas de consumo alimentario específicas se manifiesta, con relativa frecuencia, en una exacerbada preocupación por la imagen corporal, por la salud, por el mantenimiento de una línea esbelta y una perpetua lozanía, tal y como corresponde a una sociedad que se empeña en negar el inevitable deterioro de todo proceso vital, en definitiva, la muerte. Se trata del mundo narcisista posmoderno que, a partir de la pérdida de vigor de los grandes referentes y utopías que otrora aglutinaron la conciencia colectiva, se ha volcado hacia la vivencia "a tope" de la mera fugacidad del presente más inmediato ${ }^{6}$, hacia la recreación en la propia autoimagen física que, ante el desencanto político y con respecto a cualquier forma de militancia, se erige en referente fundamental de una identidad básicamente desprovista de la conciencia inherente a cualquier compromiso de control colectivo del orden social o de transformación de éste. En el caso

6. "Vivir el presente sólo en el presente y no en función del pasado y del futuro es la pérdida del sentido de la continuidad histórica [...]. Hoy vivimos para nosotros mismos, sin preocuparnos por nuestras tradiciones y nuestra posteridad” (Lipovetsky, 1990: 51). 
de nuestro país, una actitud similar a ésta es la característica de algunos sectores otrora "progresistas" que, en cierto modo, tratan de sublimar así las rutinas de su cotidianeidad, tras la vivencia del sentimiento de impotencia para transformar la realidad social ${ }^{7}$. Se trata del comportamiento consumista de una generación que ha ido sustituyendo, paulatinamente, sus sueños de "cambio del sistema" por unos valores más cuantificables y asequibles, que actúan como sucedáneos mediante los que, de algún modo, se pretende satisfacer el deseo vital, en otro tiempo "revolucionario" de una serie de yupies triunfadores (o de aspirantes a serlo). Éstos tienden a reemplazar la no siempre bien fundamentada y exenta de ingenuidad confianza en la utopía que les moviera en sus ardorosos años juveniles por los ideales narcisistas del culto al cuerpo y de la exquisitez en el comer y en el vestir.

\section{Bibliografía}

Abad Balboa, Carlos; Garcla Delgado, José Luis (1990). "La agricultura y la alimentación: una nueva etapa de cambio estructural» en GARCfA DELGADO, José Luis (1990). Economía Española de la Transición y la Democracia. Londres: CIS.

Albrow, Martin (1990). "Introduction" to Albrow, Martin; KING, Elizabeth, Globalization, Knowlwdgw and Society. Londres: Sage Publications and ISA.

BARCELO VILA, Vicente (1993). "GATT y Agricultura: mediación en un diálogo necesario", en El desarrollo rural andaluz a las puertas del siglo XXI. Sevilla: Junta de Andalucía.

BAUDRILLARD, Jean (1976). La génesis ideológica de las necesidades. Barcelona: Anagrama. BERGER, Peter; LUCKMAN, Thomas (1979). La construcción social de la realidad. Buenos Aires: Amorrortu.

BOURDIEU, Pierre (1988). La distinción. Criterio y bases sociales del gusto. Madrid: Taurus.

BouRdieu, Pierre (1976). "Anatomie du goût» Actes de la recherche en sciences sociales, $\mathbf{n}^{\circ}$ 11, 2-112 (Con M. de Saint Martin).

BourdieU, Pierre (1971). «Champ du pouvoir, Champ intellectuel et habitus de classen. Scolies, 1, 7-26.

Briz. EsCribano, Julián (1990). Publicidad en el sistema Agroalimentario. Un Análisis comparativo internacional. Análisis de los casos en España, EE.UU. y la R.F. Alemana. Madrid: Ediciones Mundi-Prensa.

ClARKE, Simon (1990). "The Crisis of Fordism or The Crisis of Social Democracy?" Telos, 83.

"El enigma del GATT" (1993-1994). Cooperación Agraria, no 7, Madrid.

ENTRENA DURÁN, Francisco (junio de 1994). «Las nuevas funciones del agro y el desatrollo rural: del productivismo al énfasis en la calidad». Rivista di Economia Agraria, a. XLIX, $n^{\circ} 2$, Istituto Nazionale di Economia Agraria, Roma.

ENTRENA DURAN, Francisco (1995). «Referentes del cambio social en el medio rural: un modelo de análisis en el contexto de la globalización», Texto inédito de la ponen-

7. Los suplementos semanales de un medio de comunicación de referencia dominante para tales sectores sociales como el diario El País suelen hacerse eco de esa actitud ante el consumo, a la vez que contribuyen a su reproducción social. 
cia presentada al III Coloquio Hispano-Portugués de Estudios Rurales, Lisboa, mayo de 1995.

GOFFMAN, Erving (1987). La presentación de la persona en la vida cotidiana. Buenos Aires: Amorrortu-Murgía.

Gracia, Azucena; AlBISU, Luis Miguel (1994). «La dieta española, en transición». El Boletin, $\mathrm{n}^{\circ}$ 18, diciembre, Ministerio de Agricultura, Pesca y Alimentación.

Habermas, J. (1987). Teoria de la Acción Comunicativa II. Critica de la Razón Funcionalista. Madrid: Taurus.

HELD, David (1991). «A democracia, o Estado-Nacao e o Sistema Global», trad. de Regis de Castro Andrade, Lua Nova, n. 23, Sao Paulo, p. 145-194.

INGLEHART, Ronald (1991). El cambio cultural en las sociedades industriales avanzadas. Madrid: CIS/S XXI.

JORDANA, Jorge (1994). «La competitividad de la industria alimentaria española». Papeles de Economia Española, números 60/61, Madrid.

HSAC (Hechos y cifras del Sector Agroalimentario Español) (1995). Madrid: Ministerio de Agricultura, Pesca y Alimentación.

LAMO DE ESPINOSA, Jaime; FIEL ASENJO, Carmen (1994). «Situación y perspectivas del sector de distribución alimentaria». Papeles de Economía Española, números 60/61, Madrid.

Le Heron, Richard (1993). Globalized Agriculture. Political Choice. Oxford: Pergamon Press LTD.

LIPOVETSKY, G. (1990). La era del vacío. Ensayos sobre el individualismo contemporáneo. Barcelona: Anagrama.

RAMOS REAL, Fernando (1993). «Exigenciai de reestructuración comercial y organizativa del sector agroalimentarion, en El desarrollo rural andaluz a las puertas del siglo XXI. Sevilla: Junta de Andalucía.

ROBERTSON, Roland (1993). Globalization. Social Theory and Global Culture. Londres: Sage Publications.

RODRIGUEZ ZúNIGA, Manuel; SORIA GUTIÉRREZ, Rosa (1986). Lecturas sobre el Sistema Agroalimentario en España. Ministerio de Agricultura, Pesca y Alimentación/Universidad Internacional Menéndez Pelayo.

RODRIGUEZ ZÚNIGA, Manuel; SANZ CAÑADA, Javier (1994). «Reestructuración y estrategias empresariales de la industria agroalimentaria». Papeles de Economía Española, números 60/61, Madrid.

SAC. El Sector Agroalimentario en Cifras, (1993). Madrid: Ministerio de Agricultura, Pesca y Alimentación.

SHILLING, Chris (1993). The body and Social Theory. Londres: Sage publications. Titos, A. (1992). Cambios en el consumo agroalimentario de los paises ribereños del Mediterráneo (1972-1986). Madrid: Instituto Nacional de Investigación y Tecnología Agraria y Alimentaria. 